\title{
ORIENTACIONES EDUCATIVAS PARA LA FORMACIÓN JURÍDICA (PENAL)
}

\author{
Educational approaches to the training of lawyers (criminal law)
}

Luis Felipe Guerrero Agripino ${ }^{*^{*}}$

Sumario:

Introducción. 1. Trascendencia social del Derecho (penal). 1.1. El rol de la educación en el fortalecimiento del Estado de Derecho. 2. Bases de la formación jurídica. 2.1 Marco de referencia. 2.2 Los modelos: educativo y académico. 2.3 Recapitulación. 3. Pautas para el diseño curricular en los programas de licenciatura en Derecho. (Énfasis en el área penal). 3.1 Punto de partida. 3.2 Estructura curricular. 3.3 Los actores y el aprendizaje como punto de encuentro. 4.Última consideración. 5. Fuentes de consulta.

Resumen: La calidad educativa en los estudios jurídicos representa un factor importante en el fortalecimiento del Estado de Derecho. Esta situación se hace más patente en el ámbito de la formación jurídico penal dadas las transformaciones recientes al sistema de justicia penal en México. Es así como cobra relevancia analizar las bases educativas que sustentan la formación jurídica; particularmente, sobre los conocimientos, habilidades, destrezas y competencias que requiere el profesional del Derecho ante los desafíos actuales.

Palabras clave: Formación jurídica penal, Estado de Derecho, cultura de la legalidad, modelo educativo, modelos académicos.

Abstract: The quality of education in law studies is an important factor in strengthening the rule of law. This situation is more evident in the field of criminal justice training. The quality of education in the said area, deserves general educational approaches and specific reference frames.

Keywords: Criminal legal training, educational model, academic models.

\section{INTRODUCCIÓN}

Sin dejar de lado el preocupante rezago educativo general en México, en los últimos años se alcanza a apreciar un incremento considerable de egresados de la licenciatura en Derecho. También, en tiempos recientes, se han propiciado cambios sustanciales al sistema de justicia penal en nuestro país. Consideramos oportuno asociar ambas circunstancias para plantear algunas interrogantes: ${ }_{¿}$ El incremento de los egresados de derecho responde al fortalecimiento del Estado de Derecho en nuestro país? ¿Bajo qué bases educativas se construye la formación jurídica? ¿Qué conocimientos, habilidades, destrezas y competencias requiere el

\footnotetext{
${ }^{1^{*}}$ Rector del Campus Guanajuato de la Universidad de Guanajuato y profesor del Departamento de Derecho en la propia Institución. Miembro del Sistema Nacional de Investigadores, nivel II.
} 
profesional del Derecho ante los desafíos que impone el nuevo sistema de justicia penal en México? Esas preguntas sostienen el desarrollo del presente artículo.

Adoptamos como principio sustancial de nuestro enfoque el carácter instrumental del Derecho, y el papel que debe desempeñar en las transformaciones de la sociedad. Particularmente, por los valores que protege y por los medios que emplea para la salvaguarda de ellos, el Derecho penal debe ser celosamente cuidado, tanto en su diseño como en su aplicación. Estas cuestiones inciden de manera directa en el fortalecimiento del Estado de Derecho, y a ellas nos referimos en el primer apartado de este estudio.

En el segundo apartado abordamos un panorama educativo general, para luego enfocarnos a las particularidades de la formación jurídica. Así, destinamos el último apartado a la concreción de una estructura curricular basada en un modelo educativo que ponga como centro de atención el aprendizaje del estudiante; que se le asuma como constructor de su propio conocimiento con la capacidad de otorgarle un significado singular al aprendizaje adquirido.

En el desarrollo de dicha estructura tratamos de ejemplificar tanto contenidos como habilidades, destrezas, capacidades o competencias inherentes a la formación jurídica, con enfática referencia a la formación jurídica penal.

La finalidad de la presente colaboración es la de tratar de enmarcar, en breves líneas, una ruta de análisis sobre el tema abordado. Desde luego, dicha pretensión es acorde a nuestra formación disciplinar, a sabiendas de que es susceptible de analizarse bajo enfoques teóricos pedagógicos de mayor profundidad.

\section{TRASCENDENCIA SOCIAL DEL DERECHO (PENAL)}

El Derecho es una disciplina omnipresente en nuestras sociedades. Es difícil encontrar alguna relación interpersonal o social que no esté o que no pueda estar regulada jurídicamente. A pesar de los esfuerzos por superar la implementación del orden jurídico, en realidad la tendencia es que cada vez se acuda con mayor frecuencia a él. ${ }^{2}$

Derivado de esa tendencia, merece la pena preguntarnos si nuestras sociedades son mejores al contar con una esfera amplia de organización jurídica y si dicha amplitud ha propiciado entornos más justos. Lo cierto es que en las sociedades antiguas existían realidades y mecanismos jurídicos menos complejos. Posteriormente, derivado de la revolución industrial emergieron otro tipo de relaciones que dieron lugar a problemas más diversos y ahora la hipótesis que plantea el abolicionismo o reducción significativa de Derecho parece ser cada vez más lejana. ${ }^{3}$

Ante la imposibilidad de la convivencia sin el Derecho, lo que resulta pertinente plantear es la trascendencia del orden jurídico en el desarrollo y transformación de las sociedades. Es decir, el Derecho adquiere relevancia en la medida que sirve como un factor posibilitador del cambio social y no como un obstáculo a dicho cambio. ${ }^{4}$ Es así como el Derecho adquiere

\footnotetext{
${ }^{2}$ Vid. ATIENZA, Manuel, El sentido del Derecho, 2da. Edición revisada y segunda reimpresión, Ariel Derecho, Barcelona, 2004, pp. 15-17.

3 Vid. ATIENZA, Op. Cit., p. 20.

4 NOVOA MONREAL, Eduardo, El Derecho como obstáculo al cambio social, Siglo XXI editores, México, 1975, pp. 15-17.
} 
su relevancia y legitimidad, dado que no puede ser entendido como un fin en sí mismo, sino como un medio para la consecución de fines socialmente relevantes.

Son diversas, complejas y vertiginosas las transformaciones de la sociedad actual. La notoria evolución científica y tecnológica ha incidido significativamente en el bienestar de las personas. La apertura de los mercados, la enorme posibilidad de obtener información oportuna, casi al instante, y la de establecer contacto con las personas en cualquier parte del mundo, indudablemente nos otorgan un escenario de realización individual y de interacción social impensables hace algunas décadas. Lo que a la juventud actual le parece ahora un entorno normal, para nuestros ancestros inmediatos y para nosotros, hace algunos años, hubiera parecido un mundo de fantasía.

Ese estado de cosas lo podríamos categorizar como evolución. Pero ello representa una cara de la moneda y es importante ubicar la otra cara; es decir, la parte negativa. Piénsese, por ejemplo, en los nuevos riesgos a los que nos enfrentamos y que también hace apenas algunos años resultaban inimaginables; riesgos -en términos de Ulrich Beck- referidos a daños no delimitables, globales y, con frecuencia, irreparables que perjudican a un gran número de personas y que emanan del hacer humano. ${ }^{5}$ Tales riesgos y daños involucran a diferentes campos del Derecho y en muchas ocasiones comprenden ámbitos de orden transnacional o regulan fenómenos altamente complejos. Por ejemplo: el tratamiento jurídico del medio ambiente, los derechos de los consumidores, la complejidad de las relaciones laborales; la regulación de los avances de la biología, la genética, la energía nuclear, la informática, las comunicaciones; la regulación de los mercados internacionales, las operaciones financieras transnacionales, etc. ${ }^{6}$

Así, ante los fenómenos cambiantes de la sociedad contemporánea, el Derecho sigue manteniendo su presencia polifacética: en la regulación de conductas, ex ante y ex post; en la resolución de conflictos, en la configuración de condiciones de vida, en la organización del poder social y en la legitimación de dicho poder.7

Ante esta omnipresencia del Derecho, para los fines de nuestro estudio, se establece una doble delimitación: el contexto jurídico mexicano y el ámbito jurídico penal.

Por lo que respecta al contexto mexicano, es de destacar un gran pendiente en la agenda nacional: el fortalecimiento del Estado de Derecho. Mientras no se logre tal fortalecimiento difícilmente podremos dar pasos en otros ámbitos como el económico, el político o el social.

En relación con el ámbito jurídico penal, hemos de destacar su trascendencia desde los valores que protege y los medios que emplea. El Derecho penal, en su concepción más amplia, es el más riguroso de los Derechos. Es el que debe ser más cuidado pues de su aplicación o no, o de su aplicación injusta suelen derivarse consecuencias que afectan gravemente a las personas. No por nada Ignacio Berdugo, respaldándose en un aserto de Alfonso de Castro,

\footnotetext{
5 BECK, Ulrich, "De las sociedad industrial a la sociedad del riesgo", (trad.: Del Rio Hermann), en: Revista de Occidente, núm. 150, 1993, pp. 19 y ss., citado por SILVA SÁNCHEZ, José María, La expansión del Derecho penal. (Aspectos de la política criminal en las sociedades postindustriales), Civitas, Madrid, 1999, pp. 21 y ss.

6 Vid. GUERRERO AGRIPINO, Luis Felipe, "Nuevos paradigmas de la investigación jurídica en el concierto de la sociedad mundializada”, en: Hacia dónde va la ciencia en México (Investigación jurídica), Coordinador: Luis Felipe Guerrero Agripino, Coedición: CONACYT, Academia Mexicana de Ciencias y Consejo Consultivo de Ciencias de la Presidencia de la República, México, 2014, pp. 56-58.

7 Vid. PRIETO SANCHIZ, Luis, Apuntes de teoría del Derecho, Trotta, Madrid, 2005, pp. 35 y 36.
} 
hace patente la consideración del carácter subsidiario del Derecho penal al afirmar que sus normas son "las almenas y los cañones de los demás derechos".

\section{I.I. EL ROL DE LA EDUCACIÓN EN EL FORTALECIMIENTO DEL ESTADO DE DERECHO}

En el concierto del desarrollo de las naciones, indiscutiblemente el conocimiento y la educación representan pilares insoslayables. En sentido estricto, lo que distingue a los países pobres de los ricos no es sólo el mayor o menor capital que poseen sino también el conocimiento que generan y cómo lo optimizan, así como el cúmulo de beneficios -tangibles e intangibles- que detona una educación sólida e integral en los miembros de la sociedad y, por ende, en la comuna misma.

Obviamente, en un contexto global, la cuestión se torna compleja como lo referimos de manera general líneas arriba. Los seres humanos hemos avanzado de manera estrepitosa, por ejemplo, en telecomunicaciones y tecnología, pero mantenemos problemas de antaño: millones de personas no tienen qué comer; la guerra y la violencia se extienden y adquieren expresiones cada vez más crueles; no hemos sido lo suficientemente capaces para cuidar y aprovechar nuestros recursos naturales; estamos cada vez más informados, más "conectados" o "interconectados", aunque valdría la pena preguntarnos si estamos mejor comunicados, si estamos en un buen momento en cuanto a la efectividad de las relaciones interpersonales; entre otros factores que integran el saldo negativo.

Todo ello adquiere dimensiones particulares en países como México. Países como éste, con enormes brechas de desigualdad, pero con grandes fortalezas como sus recursos naturales, sus energéticos, su biodiversidad, su capacidad hídrica, su producción de alimentos, ¿qué requiere? Requiere, por ejemplo, transformación productiva, innovación, generación de conocimiento y una proyección más amplia del humanismo, del arte, de la cultura en múltiples dimensiones. Es decir, más y mejor educación.

Hablar de educación con calidad es hablar de diversos beneficios para la sociedad. Uno de esos beneficios incide, como lo hemos referido, en el fortalecimiento del Estado de derecho. Cobra injerencia, pues indirectamente en la medida que una sociedad entre más educada esté, mayor será el grado de consolidación de su cultura de la legalidad, lo cual adquiere relevancia directamente cuando hablamos de la educación particular de los profesionistas o mejor dicho en los profesionales del Derecho. Derivado de ello nos surgen dos preguntas: ¿Y bajo qué bases se orienta tal educación específica? ¿Cómo podemos incidir en la mejor formación de quienes estudian Derecho? En las siguientes líneas nos detendremos en ello, lo cual representa la parte toral del presente trabajo.

\section{BASES DE LA FORMACIÓN JURÍDICA}

De las líneas desarrolladas en los apartados previos recapitulamos una idea principal: el Estado de Derecho es un eje central de las políticas públicas y un elemento crucial para lograr

\footnotetext{
8 BERDUGO GÓMEZ DE LA TORRE, Ignacio, "La Universidad de Salamanca y el estudio del Derecho Penal”, en: (VVA.AA) La influencia de la ciencia penal en Iberoamérica, t. I, coord.: Miguel Ontiveros Alonso y Mercedes Peláez Ferrusca, Instituto Nacional de Ciencias Penales, México, 2003, p. 15 y 16. Enmarca su ensayo haciendo énfasis en que tres son las preguntas que nos debemos formularnos aquellos que nos dedicamos al estudio del derecho penal: cuál es el fundamento del derecho a castigar, qué contenido deben tener las leyes y qué interpretación debe darse a las normas para facilitar su aplicación.
} 
niveles más elevados de desarrollo económico y democracia política. Para que un Estado logre tal pretensión requiere necesariamente de un conjunto de operadores con suficientes capacidades y técnicas, a fin de estar en posibilidades reales de lograr el funcionamiento adecuado del orden jurídico y de las instituciones. Así como un sistema de salud no puede operar adecuadamente sin una coordinación de expertos, tampoco es posible hacer lo propio en el sistema jurídico, sin operadores capaces. ${ }^{9}$ En palabras de Pérez Hurtado: ${ }^{10}$ "La calidad y estructura de la educación jurídica en México repercute directamente en la calidad de los servicios profesionales que prestan los abogados y en la calidad y eficacia del sistema jurídico mexicano".

Ahora, ¿qué entendemos por calidad de los abogados? ¿Será proporcional la calidad con la cantidad de licenciados en Derecho en nuestro país? Y, más específicamente, ¿qué características o enfoques requieren los profesionales del Derecho cuya dedicación se encuentra preponderantemente en el ámbito jurídico penal?

Con la pretensión de responder las interrogantes anteriores, asumiremos un marco de referencia general para luego concretarlo al ámbito de la formación jurídica y, después, especialmente, a la formación jurídica penal.

\subsection{MARCO DE REFERENCIA GENERAL}

La educación con calidad se manifiesta en el desarrollo de la sociedad y en el ámbito individual, pues representa un proceso a través del cual cada persona puede llegar a dirigir con sentido su propia vida. Es, en términos de Federico Mayor Zaragoza: "aprender a ser uno mismo"; ${ }^{11}$ es encontrar y consolidar el camino en el que somos aprendices permanentes de acuerdo a nuestra propia existencia. En suma, la educación nos permite adquirir soberanía personal para no estar al dictado de nadie y para que tengamos nuestras propias respuestas sobre las cuestiones esenciales.

Hablar de educación es referirnos a la formación integral de la persona. Se trata de dejar en ella una base de conocimientos, habilidades, actitudes y valores. Se trata también de que sepa qué hacer con todo ello y qué puede otorgarle desde su esencia personal.

La educación ha de proporcionar herramientas para formar ciudadanos activos, preparados para afrontar un mundo complejo, con su propia iniciativa y criterios emanados desde la condición humana. En ella radica la base de todo entendimiento; es nuestra condición humana la que nos puede llevar a dilucidar la esencia de los distintos comportamientos y de las diferentes percepciones del mundo. En el marco de la condición humana se ha de situar el debate sobre el espíritu innovador, el carácter emprendedor y el éxito o fracaso de la creatividad. ${ }^{12}$

En palabras de Ángel Gabilondo: ${ }^{13}$

\footnotetext{
9 Fix Fierro, en la presentación del libro: PÉREZ HURTADO, Luis Fernando, La futura generación de abogados mexicanos. (Estudio de las escuelas y los estudiantes de Derecho en México), UNAM y Centro de Estudios sobre la Enseñanza y Aprendizaje del Derecho A.C (CEEAD), México, 2009.

${ }^{10}$ PÉREZ HURTADO, Luis Fernando: op. cit., p. 189.

${ }^{11}$ Así lo sostuvo en la entrevista publicada en la revista une libros, Unión de Editoriales Universitarias Españolas, $\mathrm{n}^{\circ} 20$, primavera 2010, p. 12.

${ }^{12}$ Vid. GONZÁLEZ, Felipe, En busca de respuestas. (El liderazgo en tiempos de crisis), Debate, Barcelona, 2013, pp. 85 y ss.

${ }^{13}$ GABILONDO, Ángel, Palabras a mano, Seix Barral, Barcelona, 2010, pp. 28 y 29.
} 
“(...) la educación es, como señalamos fundamentalmente la capacidad de llegar a ser artífice de la propia vida y no un simple artefacto, producto del quehacer de otros. Y, conduce, en última instancia, a considerar que es preciso contar con los demás, y dar una dimensión común, comunitaria, a nuestras decisiones y acciones. De lo contrario, sólo seremos esclavos o literalmente idiotas, tan privados y particulares que, o bien careceremos de comunidad, o mostraremos una manifiesta incapacidad para los asuntos comunes y públicos (...)

(...) Es tiempo, siempre lo es, de pensar en qué consiste la educación. Ciertamente se muestra en la capacidad de comunicarse, de tener criterio propio, de argumentar, de comprender, de resolver, de aprender (...) No hay método para encontrar tesoros y tampoco hay un método para aprender."

Educarnos es estar preparados para ser protagonistas de nuestra propia vida; para transformar nuestra vida, inventar sus contenidos. ${ }^{14}$ Todo ello, conscientes de que el proceso de formación, de aprendizaje es permanente, para toda la vida. En términos de Karl Popper: "La educación y la cultura no es algo que se herede, se labra por medio del esfuerzo". ${ }^{5}$

\subsection{LOS MODELOS: EDUCATIVO Y ACADÉMICO}

Si bien no existen "recetas mágicas" en el proceso educativo, sí es factible diseñar los grandes derroteros que marquen las posturas y orientaciones pedagógicas.

Los ideales y principios educativos se suelen incorporar en un marco conceptual identificado como el modelo educativo, el cual adquiere su sello específico en razón de la institución educativa del cual emerge. En palabras de Tünnermann, el modelo educativo "es la concreción, en términos pedagógicos, de los paradigmas educativos que una institución profesa y que sirve de referencia para todas las funciones que cumple (docencia, investigación, extensión, vinculación y servicios), a fin de hacer realidad su proyecto educativo". ${ }^{16}$

El modelo educativo representa una carta de navegación general, aplicable a todas las áreas del conocimiento y disciplinas. Representa un rumbo a seguir. Ahora, desde nuestro punto de vista, por lo menos en lo que respecta a las instituciones de educación superior públicas en el país, el rumbo lo podemos ubicar desde la propia Constitución Política de los Estados Unidos Mexicanos. En su artículo 3, se señala:

$$
\text { “[...] }
$$

\footnotetext{
${ }^{14}$ SAVATER, Fernando, Ética de URGENCIA, Ariel, Barcelona, 2012, p. 15. En similares términos, vid. VILA MERINO, Eduardo S., "Ciudadanía, equidad e innovación: reflexiones sobre la política de responsabilidad social de las universidades", en: Innovación educativa, v. 12, tercera época, mayo-agosto 2012, México, p. 65, al referir que hay que llevar los ideales democráticos y emancipatorios al terreno de la educación. Cita a Grundy: "En la simple consecuencia concreta de lo determinado de antemano por la teoría no hay libertad, aunque uno se adhiera a la teoría particular que se implementa en la realidad. La emancipación radica en la posibilidad de emprender acciones de manera autónoma. Esa acción puede estar informada por determinadas ideas teóricas, pero no está prescita por ellas".

${ }^{15}$ POPPER, Karl R., La responsabilidad de vivir. (Escritos sobre politica, historia y conocimiento), trad.: Concha Roldán, Paidós, primera edición en esta presentación, primera edición 1995, España, 2012, 134.

16 TÜNNERMANN BARNHEM, Carlos, Modelos educativos y académicos, Hispamer, Nicaragua, 20o8, p. 15. 
La educación que imparta el Estado tenderá a desarrollar armónicamente, todas las facultades del ser humano y fomentará en él, a la vez, el amor a la Patria, el respeto a los derechos humanos y la conciencia de la solidaridad internacional, en la independencia y en la justicia.

El Estado garantizará la calidad en la educación obligatoria de manera que los materiales y métodos educativos, la organización escolar, la infraestructura educativa y la idoneidad de los docentes y los directivos garanticen el máximo logro de aprendizaje de los educandos.

I. Garantizada por el artículo 24 la libertad de creencias, dicha educación será laica y, por tanto, se mantendrá por completo ajena a cualquier doctrina religiosa;

II. El criterio que orientará a esa educación se basará en los resultados del progreso científico, luchará contra la ignorancia y sus efectos, las servidumbres, los fanatismos y los prejuicios.

\section{Además:}

a) Será democrático, considerando a la democracia no solamente como una estructura jurídica y un régimen político, sino como un sistema de vida fundado en el constante mejoramiento económico, social y cultural del pueblo;

b) Será nacional, en cuanto -sin hostilidades ni exclusivismos- atenderá a la comprensión de nuestros problemas, al aprovechamiento de nuestros recursos, a la defensa de nuestra independencia política, al aseguramiento de nuestra independencia económica y a la continuidad y acrecentamiento de nuestra cultura;

c) Contribuirá a la mejor convivencia humana, a fin de fortalecer el aprecio y respeto por la diversidad cultural, la dignidad de la persona, la integridad de la familia, la convicción del interés general de la sociedad, los ideales de fraternidad e igualdad de derechos de todos, evitando los privilegios de razas, de religión, de grupos, de sexos o de individuos, y

d) Será de calidad, con base en el mejoramiento constante y el máximo logro académico de los educandos;

$[\ldots]$."

El texto transcrito tiene un alto contenido ideológico. Aunado a ello, es de destacar que al desiderátum constitucional corresponde acompañarle de elementos específicos que permitan orientar todas aquellas habilidades, destrezas, conocimientos, actitudes, valores y capacidades que hagan palpable un paradigma educativo en la formación del estudiante. Lo anterior debe suceder en todas las disciplinas que se cultiven en una institución de educación superior.

Lo transcendente es definir cuáles son esos elementos y cuál debe ser su contenido. No hay una postura única. Cada institución establece su propio marco. Para fines ejemplificativos, referiremos el caso de la Universidad de Guanajuato. En su Ley Orgánica, al definirse su misión, se plasman las bases de su modelo educativo. Su artículo 4 estipula: 
"En la Universidad, en un ambiente abierto a la libre discusión de las ideas, se procurará la formación integral de las personas y la búsqueda de la verdad, para la construcción de una sociedad libre, justa, democrática, equitativa, con sentido humanista y conciencia social. En ella regirán los principios de libertad de cátedra, libre investigación y compromiso social y prevalecerá el espíritu crítico, pluralista, creativo y participativo.

Para realizar su misión, la Universidad atenderá tanto a las exigencias de su entorno inmediato, como a las que plantea su inserción en la comunidad nacional e internacional."

Asimismo, en su Plan de Desarrollo Institucional 2010-2020, en su atributo número 9 que caracteriza a su visión, se evoca la pertinencia de: ${ }^{17}$

"Poseer un modelo educativo centrado en el aprendizaje de los estudiantes, sustentado en un currículo flexible que propicia que los alumnos puedan aprovechar toda la oferta educativa de la institución para su formación y el fortalecimiento de sus vocaciones, así como la realización de estudios complementarios en instituciones nacionales y extranjeras. El Modelo Educativo es plural, con apertura a diferentes posturas pedagógicas, de manera tal que la Universidad de Guanajuato innova en los paradigmas educativos y genera ideas nuevas.

\section{$[\ldots]$}

Los egresados del nivel superior son apreciados por su formación humanista, creatividad, liderazgo, iniciativa, honestidad, compromiso ético y solidario con el desarrollo sustentable global. Por su actitud de trabajo y cooperación, espíritu crítico y emprendedor, y por sus sólidas competencias en comunicación oral y escrita en español y en un segundo idioma; por su capacidad de adaptación a una gran variedad de situaciones y contextos, para aprender nuevos conocimientos, planear, asumir responsabilidades y tomar decisiones en forma autónoma, resolver problemas, formular y desarrollar proyectos, y trabajar bajo presión y en equipo."

Para darle mayor contenido a la construcción planteada, también merece la pena acudir a diversos parámetros internacionales. Por ejemplo, la UNESCO, en la "Declaración Mundial sobre la educación para el siglo XXI", establece que para lograr una formación integral y armónica en el plano intelectual, humano, social y profesional, en el modelo educativo debe permear: "El aprendizaje permanente, el desarrollo autónomo, el trabajo en equipo, la comunicación con diversas audiencias, la creatividad y la innovación en la producción de conocimiento y en el desarrollo de tecnología, la destreza en la solución de problemas, el desarrollo de un espíritu emprendedor, la sensibilidad social y la comprensión de diversas culturas". 18

Desde luego, todo contenido del modelo educativo será susceptible de analizarse y discutirse a la luz de diferentes marcos teóricos. Es importante aclarar que no es esa la finalidad de este artículo, ni por el espacio ni por las propias limitaciones disciplinares de quien lo sus-

\footnotetext{
${ }^{17}$ Cfr.: Modelo Académico de la Universidad de Guanajuato, 2011, editado por la propia institución, en ese año.

18 Así lo ejemplifica TÜRNNEMANN, al referirse al Modelo Educativo de la Universidad Veracruzana, Op. Cit., p. 17 .
} 
cribe. ${ }^{19}$ La pretensión es sólo ofrecer un panorama esencial para nuestro enfoque particular que más adelante asumiremos.

Como hemos reiterado, el modelo educativo de una institución representa el esquema marco, mismo que debe permear en cada disciplina, en cada programa, con las particularidades y enfoques particulares. Esa concreción configura lo que entendemos por modelo académico. No existe uno, sino varios modelos académicos. Los que correspondan a los diferentes niveles educativos. De esta manera, cada programa perseguirá el paradigma educativo expresado en el modelo educativo y la concreción del modelo académico al cuál ha de ceñirse.

\subsection{RECAPITULACIÓN}

Del desarrollo anterior, podemos asumir como preponderantes los siguientes ejes orientadores en la formación general que, desde luego, resultan aplicables al campo jurídico, y particularmente al ámbito penal.

a)La educación debe asumir como punto central de su proceso el aprendizaje del estudiante. Por más brillante que resulte un profesor en el desarrollo de su práctica docente, si su talento no incide en el desarrollo autónomo del estudiante no podemos hablar de un éxito docente; el éxito docente no se mide en la capacidad del profesor para impresionar al alumno, sino en lo que deja en él; en el legado educativo que le permite al estudiante no sólo deslumbrarse con la luminosidad del profesor sino que el estudiante pueda contar con la posibilidad de trascender.

b) El desarrollo del conocimiento disciplinar debe permanecer abierto al involucramiento con otras disciplinas. El encasillamiento unidisciplinar, además de limitado puede resultar peligroso. Sobre ello resulta oportuna la crítica que hace Edgar Morín a la falta de adecuación entre saberes discordes, troceados, encasillados en disciplinas, mientras que por otro lado nos encontramos ante realidades o problemas cada vez más multidicsiplinarios, transversales, multidimensionales, trasnacionales y globales. En virtud de ello se requiere visualizar conjuntos complejos, las interacciones entre las partes y el todo, la determinación de entidades multidimenscionales y la ubicación de problemas esenciales.20

c) La innovación educativa debe permear tanto en los instrumentos que respaldan el proceso educativo (el uso de tecnologías, dominio de idiomas, etc.), como en los métodos y técnicas que faciliten el aprendizaje. Desde luego, sin dejar de reconocer la forma diferente de hacer las cosas para mejorarlas y la creatividad no se construyen con recetas.

\footnotetext{
${ }^{19}$ No pasamos por alto la discusión que se deriva al otorgarle a los modelos educativos una categorización específica. En los últimos años ha cobrado especial atención la precisión que se otorga a ciertos modelos "por competencias". Al margen de la controversia que se suscita por carecer dicho término de una expresión unívoca, estimamos que, en todo caso, significaría otorgarle una denominación a un modelo por una de sus partes que aunque importante es más que esa parte. Sobre dicha tendencia, vid. GOÑI ZAVALA, Jesús Ma., El espacio europeo de educación superior, un reto para la universidad. (Competencias, tareas y evaluación, los ejes del currículum universitario), OCTAEDRO / ICE-UB, Barcelona, 2005.

${ }^{20}$ MORÍN, Edgar, La mente bien ordenada, trad.: Ma. José Buxó-Dulce Montesinos, Seix Berral Los Tres Mundos, sexta edición, Barcelona, 2005, pp. 13-41.
} 
d) El diseño curricular debe mantener orden, pero también flexibilidad. El currículum del programa educativo debe propiciar un margen de certeza y un cúmulo de posibilidades. Lo importante es que el estudiante se apropie del currículo, para su formación trascendente y autónoma, y no que el currículo se apropie del estudiante para encasillarlo y limitarlo. Para ello, es importante que el estudiante tenga opciones de movilidad académica. Es decir, de realizar cursos en otras entidades de su institución o en cualquier otra del mundo, siempre y cuando resulten acordes a su propia formación. Y para que eso suceda es indispensable el acompañamiento académico del profesorado y del tutor, así como la facilitación de los procesos escolares por parte de la administración institucional.

3. PAUTAS PARA EL DISEÑO CURRICULAR EN LOS PROGRAMAS DE LICENCIATURA EN DERECHO. (ÉNFASIS EN EL ÁREA PENAL)

\subsection{PUNTO DE PARTIDA}

Para orientar el diseño curricular de los programas de licenciatura en Derecho es necesario comenzar por plantearnos ¿qué hace un abogado? La respuesta a dicho planteamiento es relativamente sencilla de responder: para la generalidad de las personas, un abogado es aquel profesionista dedicado a liberar personas de las cárceles o viceversa; a atender procesos para el embargo de bienes o a divorciar personas, etc. Sin embargo, existe un ámbito de ejercicio profesional diferente al estrictamente litigioso. Los abogados también debemos ejercer la importante función social de crear y aplicar el Derecho, así como la de alimentar sus fuentes mediante la investigación jurídica y la de facilitar su aprendizaje entre quienes habrán de cultivarlo en cualquiera de sus ámbitos. ${ }^{21}$

Consecuentemente, el abanico de funciones, responsabilidades y actividades inherentes a la profesión de abogado posee una gran amplitud. Entre otros aspectos, nos corresponde: ${ }^{22}$

- Identificar objetos de estudio

- Describir las normas contenidas en los ordenamientos jurídicos

- Sistematizar el Derecho

- Definir, crear y utilizar conceptos

- Elaborar, clasificar y utilizar teorías

- Inferir o construir principios derivados del marco legal

- Interpretar normas

- Analizar y describir hechos

- Reflexionar sobre valores jurídicos

\footnotetext{
${ }^{21}$ Vid. CRUZ PARCERO, Juan Antonio, "Los métodos para los juristas", en: Observar la Ley (ensayos sobre metodología de la investigación jurídica), edición de Christian Courtis, Trotta, Madrid, 2006.

${ }^{22}$ Idem.

CienCIA JURÍdica. Departamento de Derecho. División de Derecho, Política y Gobierno, Universidad de Guanajuato - Año 4, No. 7, 2015
} 
- Legitimar, criticar y cuestionar regímenes políticos

- Enseñar, transmitir y difundir el conocimiento

\subsection{ESTRUCTURA CURRICULAR}

La estructura curricular para la formación del abogado requiere de diversos elementos:

I. Un contenido básico. Se refiere al estudio de los elementos básicos y comunes para la formación de todo abogado, como son: las ramas del Derecho, la filosofía del Derecho, la metodología de la investigación jurídica, derechos fundamentales, argumentación jurídica, etc.

II. Una base de especialización. Además del contenido básico, el contexto actual exige a los abogados cultivar áreas del conocimiento definidas, vinculadas al quehacer jurídico que a su vez exigen, además del estudio de las ramas del núcleo básico, otras capacidades y competencias. Por ejemplo: la criminalística, la criminología, la política criminal, etc.

La construcción de esta base en las estructuras curriculares, a su vez, hace necesaria la inclusión de modelos que permitan a los estudiantes adquirir y desarrollar competencias necesarias para afrontar las dinámicas transformaciones estructurales y procesales del sistema jurídico. Por ejemplo, en el caso de nuestro país, uno de los cambios más trascendentales se ha dado en el sistema penal acusatorio, lo cual hace imprescindible la inclusión de contenidos que doten al estudiante de las herramientas indispensables para incorporarse al mismo. Algunas de estas competencias son: ${ }^{23}$
a. Manejo integral de conflictos y crisis. ${ }^{24}$
b. Técnicas para la resolución de conflictos.
c. Técnicas de investigación criminal..$^{25}$
d. Técnicas para la interrogación estratégica. ${ }^{26}$

I. Una base de profundización. Referida a un mayor nivel de exploración y reflexión sobre parcelas del conocimiento jurídico definidas. Entre otros aspectos, el contenido de esta base

\footnotetext{
${ }^{23}$ Información retroalimentada con Mauricio Alejandro MURILLO DE LA ROSA, Consultor certificado por el Consejo de Coordinación para la Implementación del Sistema de Justicia Penal y maestro en Ciencias Jurídico Penales y con Rafael Octavio ROMO AGUIÑAGA, profesor del Departamento de Derecho de la División de Derecho, Política y Gobierno del Campus Guanajuato de la Universidad de Guanajuato y Director Jurídico de Negocios del Banco del Bajío.

${ }^{24}$ Con el objeto de proporcionar al alumno de las técnicas y herramientas que le permitan asumir el control de la situación en el manejo de conflictos y la resolución de crisis.

${ }^{25}$ Otro aspecto, es el conocimiento de técnicas de investigación criminal. Ahora el ministerio público no hace la investigación, la dirige. En consecuencia, debe de saber qué evidencias o indicios debe recabar de acuerdo a su teoría del caso preliminar. Debe saber qué debe hacerse en el lugar de los hechos. En general debe de saber obtener indicios o evidencias independientemente de donde se encuentren éstos.

${ }^{26}$ Una competencia que debe tener el abogado en este sistema de justicia es la de saber interrogar y no únicamente en cuanto a las técnicas que debe conocer, sino que estratégicamente el abogado debe de saber "con-
} 
se constituye por disciplinas tales como: medio ambiente, economía, salud, biología, psicología, policiología, arbitraje, auditoria, cibernética, etc.

II. Competencias genéricas. Se refiere a un nivel general de aptitudes o elementos idóneos que proporcione las habilidades necesarias para intervenir eficazmente en el campo jurídico. Algunas de estas competencias tienen que ver con:

a. Formas de pensar. Se refiere a la capacidad de aprendizaje; al empleo de la información obtenida, a la creatividad e innovación; a la construcción de un pensamiento crítico, a la capacidad para afrontar problemas y a la construcción y toma de decisiones, entre otros componentes.

b. Formas de trabajar. Es necesario adquirir competencias para desempeñarse eficientemente en las labores que implica el ejercicio de la profesión. Para ello, resulta indispensable saber comunicarse, realizar trabajo colaborativo, asimilar adecuadamente la presión de cada situación o problema en particular, etc.

c. Herramientas para trabajar. Lo cual supone el que los abogados cuenten con los instrumentos que les permitan realizar su función. Entre estos elementos se encuentran el dominio de idiomas, el uso de las tecnologías de la comunicación y de la información, así como el apropiado manejo de ésta y su aprovechamiento.

d. Competencias para vivir el mundo. Requerimos involucrarnos en la construcción de una mejor ciudadanía; fortalecer la responsabilidad social de los individuos frente al grupo y consigo mismo; aprender a disfrutar del entorno y de nuestras experiencias; fomentar la intuición, la capacidad de asombro y la innovación. ${ }^{27}$

\subsection{LOS ACTORES Y EL APRENDIZAJE COMO PUNTO DE ENCUENTRO}

En el proceso educativo los actores centrales son los estudiantes y los profesores reunidos en torno a un objetivo común: aprender.

Consecuentemente, la estructura curricular debe tener como punto de referencia claridad en torno a lo que cada uno de éstos representa y, en consecuencia, la definición de un modelo de cual partir para la construcción de los contenidos:

Modelo de estudiante. Se trata de seres humanos en formación, en constante crecimiento y desarrollo de capacidades. Debemos asumir que éstos son constructores de su propio conocimiento. Ellos le dan significado particular al aprendizaje adquirido.

Modelo de profesor. Profesionales que dominan un área del conocimiento y que además promueven valores y actitudes; con capacidad y competencias para trabajar con los alumnos. Esencialmente, deben ser facilitadores del aprendizaje y motivadores del uso de las competencias de los estudiantes.

Por otra parte, las estructuras curriculares deben asumir al aprendizaje como la finalidad de la enseñanza, siempre considerando que se trata de un proceso en construcción del co-

ducir" al testigo hacia donde lo quiere llevar, considerando además que su credibilidad resulta fundamental.

27 Para abundar en las competencias genéricas: Vid. GOÑI ZABALA, Jesús Ma., Op. Cit., pp. 90 y ss. 
nocimiento que implica la interacción entre el estudiante, los profesores y los distintos tipos de contenido.

Tampoco debemos dejar de lado que, la formación de los abogados en la actualidad, exige el aprendizaje innovador, de gran interacción, en el cual el papel de los actores es igualmente importante. Es decir, posee igual importancia la transmisión del conocimiento al alumno por parte del profesor como el que alumno posea la capacidad suficiente para inquirir en torno a ello. No sólo cuestión de contenidos y de datos asimilados y relacionados, sino fundamentalmente de sembrar un sentido crítico y de actitud en el alumno. ${ }^{28}$

\section{4. ÚLTIMA CONSIDERACIÓN}

Es importante abrir espacios de educación superior, brindar oportunidades de acceso a la formación profesional, pero sin dejar de lado la calidad educativa. Particularmente, en el caso de la profesión jurídica, al ser de las de mayor demanda, se incrementa el riesgo del menoscabo de la calidad. Por ello es importante insistir en el perfil mínimo que para el ejercicio de tal profesión se requiere, en todas las áreas. En el ámbito jurídico penal, por las razones antes expuestas, es menester otorgarle enfoques específicos.

Por otro lado, consideramos oportuno aclarar que para el fortalecimiento del Estado de Derecho, son varios los factores que influyen. Piénsese, por ejemplo, en la importancia de la educación en su alcance más amplio que incide en la cultura cívica, política y de legalidad. La formación jurídica es una parte, pero no el todo.

La necesidad de aprender a aprender durante toda nuestra vida tiene diversas manifestaciones. Una de ellas es la continuidad en los estudios de postgrado. Las especialidades nos ofrecen mayor conocimiento y actualidad disciplinar. Las maestrías, además de profundizar en una área disciplinar u objeto de estudio, ofrecen la posibilidad de adquirir herramientas para el ejercicio docente y la investigación. El doctorado está destinado a formar investigadores de alto nivel, capaces de generar nuevo conocimiento y de construir marcos teóricos de relieve.

Hacemos esta referencia porque, aun y cuando no es motivo de análisis de este estudio, también merece la pena advertir el cuidado de la calidad en los posgrados. En ellos, también se aprecia un incremento importante que suele rayar en una suerte de "inflación educativa", es decir, la tendencia a obtener títulos de posgrado pero sin apegarse a la esencia y razón de ser del grado obtenido. Resulta peligroso pensar que si un profesional del Derecho no tiene un postgrado por ende no está actualizado o no tiene el nivel deseable. No necesariamente es así. Lo importante es que cada profesional del Derecho ubique su perfil y se mantenga siempre actualizado. Si aunado a ello, ubica vocación para la docencia o la investigación, resultaría conveniente involucrarse en una maestría o doctorado, según el enfoque disciplinar y sus prioridades académicas y profesionales.

Desde luego, lo idóneo es generar mayores alternativas y diversidad en los posgrados, siempre y cuando, programas, instituciones y estudiantes tengan claro el por qué, el para qué y el cómo de dichos estudios superiores.

\footnotetext{
${ }^{28}$ Vid. CAPELLA, Juan Ramón, El aprendizaje del aprendizaje (una introducción al estudio del Derecho), $2 \mathrm{a}$. edición, Trotta, Madrid, 1998, p. 37.
} 
5. FUENTES

BIBLIOGRÁFICAS

ATIENZA, Manuel, El sentido del Derecho, 2da. Edición revisada y segunda reimpresión, Ariel Derecho, Barcelona, 2004.

BECK, Ulrich, "De las sociedad industrial a la sociedad del riesgo", (trad.: Del Rio Hermann), en: Revista de Occidente, núm. 150, 1993.

BERDUGO GÓMEZ DE LA TORRE, Ignacio, "La Universidad de Salamanca y el estudio del Derecho Penal”, en: (VVA.AA) La influencia de la ciencia penal en Iberoamérica, t. I, coord.: Miguel Ontiveros Alonso y Mercedes Peláez Ferrusca, Instituto Nacional de Ciencias Penales, México, 2003.

CAPELLA, Juan Ramón, El aprendizaje del aprendizaje (una introducción al estudio del Derecho), 2a. edición, Trotta, Madrid, 1998.

CRUZ PARCERO, Juan Antonio, “Los métodos para los juristas”, en: Observar la Ley (ensayos sobre metodología de la investigación jurídica), edición de Christian Courtis, Trotta, Madrid, 2006.

GABILONDO, Ángel, Palabras a mano, Seix Barral, Barcelona, 2010.

GONZÁLEZ, Felipe, En busca de respuestas. (El liderazgo en tiempos de crisis), Debate, Barcelona, 2013.

GOÑI ZAVALA, Jesús Ma., El espacio europeo de educación superior, un reto para la universidad. (Competencias, tareas y evaluación, los ejes del currículum universitario), OCTAEDRO / ICE-UB, Barcelona, 2005.

GUERRERO AGRIPINO, Luis Felipe, "Nuevos paradigmas de la investigación jurídica en el concierto de la sociedad mundializada", en: Hacia dónde va la ciencia en México (Investigación jurídica), Coordinador: Luis Felipe Guerrero Agripino, Coedición: CONACYT, Academia Mexicana de Ciencias y Consejo Consultivo de Ciencias de la Presidencia de la República, México, 2014.

MAYOR ZARAGOZA, Federico, entrevista publicada en la revista Une libros, Unión de Editoriales Universitarias Españolas, $\mathrm{n}^{\circ} 20$, primavera 2010.

MORÍN, Edgar, La mente bien ordenada, trad.: Ma. José Buxó-Dulce Montesinos, Seix Berral Los Tres Mundos, sexta edición, Barcelona, 2005.

NOVOA MONREAL, Eduardo, El Derecho como obstáculo al cambio social, Siglo XXI editores, México, 1975.

PÉREZ HURTADO, Luis Fernando: La futura generación de abogados mexicanos. (Estudio de las escuelas y los estudiantes de Derecho en México), UNAM y Centro de Estudios sobre la Enseñanza y Aprendizaje del Derecho A.C (CEEAD), México, 2009. 
POPPER, Karl R.: La responsabilidad de vivir. (Escritos sobre politica, historia y conocimiento), trad.: Concha Roldán, Paidós, primera edición en esta presentación, primera edición 1995, España, 2012.

PRIETO SANCHIZ, Luis, Apuntes de teoría del Derecho, Trotta, Madrid, 2005.

ROMO AGUIÑAGA, Rafael Octavio, Disciplinas que deberían incluirse en la currícula de la licenciatura en Derecho, México, 2015.

SAVATER, Fernando, Ética de URGENCIA, Ariel, Barcelona, 2012.

SILVA SÁNCHEZ, José María, La expansión del Derecho penal. (Aspectos de la política criminal en las sociedades postindustriales), Civitas, Madrid, 1999.

TÜNNERMANN BARNHEM, Carlos, Modelos educativos y académicos, Hispamer, Nicaragua, 2008.

VILA MERINO, Eduardo S., "Ciudadanía, equidad e innovación: reflexiones sobre la política de responsabilidad social de las universidades”, en: Innovación educativa, v. 12, tercera época, mayo-agosto, México, 2012.

Otras fuentes

Ley Orgánica de la Universidad de Guanajuato, 2007, editada por la propia institución en 2008.

Plan de Desarrollo Institucional 2010 - 2020 de la Universidad de Guanajuato, 2010, editado por la propia institución en ese año.

Modelo Académico de la Universidad de Guanajuato, 2011, editado por la propia institución, en ese año.

MURILLO DE LA ROSA, Mauricio Alejandro, documento inédito sobre Algunas competencias que podrían incluirse en la currícula académica de la carrera en Derecho derivadas del sistema acusatorio, México, 2015.

ROMO AGUIÑAGA, Rafael Octavio, documento inédito sobre las Disciplinas que deberían incluirse en la currícula de la licenciatura en Derecho, México, 2015. 